\title{
ANALISIS STRATEGI CUSTOMER RELATIONSHIP MANAGEMENT (CRM) PADA PEGADAIAN SYARIAH (Studi Kasus Pada Pegadaian Syariah Di Provinsi Jambi)
}

\author{
Busriadi \\ Institut Agama Islam Yasni Bungo \\ Email: bbusriadi@gmail.com \\ Muhammad Yasir Nasution \\ Universitas Islam Negeri (UIN) Sumatera Utara \\ Email: nasutionmy@gmail.com \\ Saparuddin Siregar \\ Universitas Islam Negeri (UIN) Sumatera Utara \\ Email: saparuddinss@yahoo.com
}

\begin{abstract}
This study analyzes customer behavior based on Customer Relationship Management performance. The research problem refers to the business phenomenon of PT. Pegadaian Syariah (Persero) Tbk. In Jambi Province. the problem of this research is how to build customer satisfaction, so that customer loyalty can be achieved as expected. The purpose of the study was formulated to seek answers to the flow of Customer Relationship Management performance. The modeling formulated in this study aims to provide a critical understanding of the concepts and measurements of customer relationship management. Researchers include elements of human resource competency, service quality, technology, and customer satisfaction as antecedents and have significant consequences on customer loyalty. This study used 110 respondents and all respondents were customers of PT. Pegadaian Syariah (Persero) Tbk. In Jambi Province. Data analysis using Structural Equation Model (SEM) with Amos 22 computer program. The results of this study indicate that human resource competency has no positive and significant impact on customer satisfaction. Meanwhile, the quality of service and technology has a positive and significant impact on customer satisfaction. The effect of customer satisfaction on loyalty also has positive consequences. Input for management that can be drawn from this customer relationship management research is an approach related to the dimensions of service quality can help managers improve customer satisfaction and customer loyalty based on Customer Relationship Management performance.
\end{abstract}

Keywords: Human Resources Competence, Service Quality, Technology, Customer Satisfaction, and Customer Loyalty Based on Customer Relationship Management Performance. 


\begin{abstract}
Abstrak
Penelitian ini menganalisis perilaku nasabah berdasarkan kinerja Customer Relationship Management. Permasalahan penelitian merujuk pada fenomena bisnis PT. Pegadaian Syariah (Persero) Tbk. Di Provinsi Jambi. permasalahan penelitian ini adalah bagaimana membangun kepuasan nasabah, sehingga loyalitas nasabah dapat tercapai sesuai harapan. Tujuan penelitian dirumuskan untuk mencari jawaban atas alur kinerja Customer Relationship Management. Permodelan yang dirumuskan pada penelitian ini bertujuan memberikan pemahaman yang kritis dalam konsep dan pengukuran manajemen hubungan pelanggan. Peneliti memasukan unsur kompetensi sumber daya manusia, mutu pelayanan, teknologi, dan kepuasan nasabah sebagai anteseden dan memiliki konsekuensi yang signifikan terhadap loyalitas nasabah. Penelitian ini mempergunakan 110 responden dan keseluruhan responden adalah nasabah PT. Pegadaian Syariah (Persero) Tbk. Di Provinsi Jambi. Analisis data mempergunakan Structural Equation Model (SEM) dengan program komputer Amos 22. Hasil penelitian ini menunjukkan bahwa kompetensi sumber daya manusia tidak berdampak positip dan signifikan terhadap kepuasan nasabah. Sementara itu Mutu pelayanan dan Teknologi berdampak positip dan signifikan terhadap kepuasan nasabah. Pengaruh kepuasan nasabah terhadap loyalitas juga berakibat positip. Masukan bagi manajemen yang bisa diambil dari penelitian customer relationship management ini adalah pendekatan yang berkaitan dengan dimensi mutu pelayanan dapat membantu manajer meningkatkan kepuasan nasabah dan loyalitas nasabah berbasis kinerja Customer Relationship Management.
\end{abstract}

Kata Kunci: Kompetensi Sumber Daya Manusia, Mutu Pelayanan, Teknologi, Kepuasan Nasabah, dan Loyalitas Nasabah Berdasarkan Kinerja Customer Relationship Management.

\title{
A.Pendahuluan
}

\section{Latar Belakang Masalah}

Mekanisme operasional yang sesuai dengan sistem ekonomi Islam dalam lembaga keuangan diyakini merupakan alternatif yang memiliki keunggulan baik bagi nasabah, bank maupun lembaga keuangan non bank agar dapat terhindar dari riba. Namun permasalahan yang terjadi di lapangan tidak berhenti di sini saja, justru makin berkembang. Sebab situasi persaingan pasar yang semakin kompleks. Hal itu terlihat jelas ketika mulai bermunculnya lembaga keuangan baru dimana mereka berlomba-lomba memberikan layanan yang kian beragam dan menarik, Salah satu contoh lembaga pegadaian. Apalagi saat ini Otoritas Jasa Keuangan (OJK) telah membuka pintu bagi pihak swasta yang ingin ikut membuka usaha 
pegadaian. Hal itu tertuang dalam POJK No.31/POJK.05/2016 tentang usaha pegadaian ${ }^{1}$.

Aturan tersebut diterbitkan berdasarkan Temuan Otoritas Jasa Keuangan (OJK) pada tahun 2017 mencatat ada lebih dari 1.000 usaha gadai swasta tak berizin di Indonesia. Kepala Eksekutif Pengawasan Industri Keuangan Non Bank (IKNB) OJK Firdaus Djaelani mengatakan kebanyakan usaha gadai ini banyak ditemukan di pinggiran jalan kotakota besar. ${ }^{2}$ Berdasarkan data resmi laporan keuangan Perum Pegadaian Semester 1 tahun 2015 terjadi penurunan kinerja perusaahaan yang berdampak pada penurunan jumlah oulet yang tersebar dibeberapa wilayah.

Tabel 1

PT. Pegadaian dan Entitas Anak

Tanggal 30 Juni 2017 dan 31 Desember 2016

\begin{tabular}{|c|c|c|c|}
\hline Uraian & 30 Juni 2016 & 30 Juni 2017 & Keterangan \\
\hline $\begin{array}{c}\text { Kantor } \\
\text { wilayah }\end{array}$ & 12 & 12 & - \\
\hline Outlet unit & 4.445 unit & 4.390 unit & Turun 65 unit \\
\hline
\end{tabular}

Sumber : wrt149 Laporan Keuangan Pegadaian Semester 1. 2015

Dari table 1 di atas menunjukan terjadinya penurunan jumlah outlet yang tersebar dibeberapa wilayah Indonesia dimana pada tahun 2016 berjumlah 4.445 unit turun menjadi 4.390 unit. Begitu juga yang terjadi di beberapa wilayah khususnya di Provinsi Jambi, terjadi penurunan yang signifikan. Pada tahun 2015 tersebar 63 outlet yang tersebar di kabupaten/kota, namun terjadi penurunan pada tahun 2017 menjadi 56 unit yang terdiri dari unit pegadaian 45 unit sedangkan unit pegadaian syariah sebanyak 11 unit $^{3}$.

1 http://www.ojk.go.id/id/regulasi/otoritas-jasa-keuangan/peraturan ojk/POJKUsaha-Pergadaian.pdf.

${ }^{2}$ Tempo.Com, Jakarta.

${ }^{3}$ http://www.pegadaian.co.id/ diakses pada tanggal 20 Desember 2017. 
Tabel 2

PT. Pegadaian dan Entitas Anak

Kantor Wilayah Jambi

\begin{tabular}{|c|c|c|}
\hline Unit Pegadaian & 2015 & 2017 \\
\hline Outlet Unit & 63 Outlet & 56 Outlet \\
\hline
\end{tabular}

Sumber : Annual Report 2015

Terjadinya penurunan outlet ini apabila tidak ditanggapi secara cepat maka akan menimbulkan persepsi negatif terhadap praktek kinerja CRM yang terjadi di PT. Pegadain. Selain itu omzet pinjaman dan rekening syariah di pegadaian rata-rata baru sekitar $12 \%$ jauh lebih rendah dibandingkan dengan OSL konvensional yang mencapai 88\%. ${ }^{4}$ Dengan adanya permasalahan tersebut pihak pegadaian tentunya harus lebih siap bersaing secara kompetitif Guna menghadapi persaingan dengan pegadaian swasta, dan meninjau kembali kinerja perusahan karena semua layanan pegadaian sama sama menggunakan aspek layanan yang berorientasi customer satisfaction atau kepuasan pelanggan. upaya yang dilakukan agar mampu bersaing dan mampu bertahan ditengah banyak nya persaingan lembaga keuangan lainya adalah dengan menggunakan strategi manajemen hubungan pelanggan sebagai tugas utama pengembangan masa depan. ${ }^{5}$

Persoalan yang paling krusial terkait dengan manajemen hubungan pelanggan adalah pengukuran keberhasilan CRM terhadap kinerja dan produktivitas perusahaan. Konsep perilaku pelanggan berdasarkan kinerja CRM diposisikan sebagai konstruk yang penting. Konsep CRM merupakan sebuah proses pencarian dan perwujudan dengan jalan menggali lebih jauh perngaruh perilaku pelanggan terhadap tercapainya sebuah kinerja yang diharapkan perusahaan. Manajemen hubungan pelanggan merupakan sebuah proses jangka panjang, dan akan menjadi sebuah proses sia-sia yang tidak

${ }^{4}$ www.pegadaian .co.id

${ }^{5}$ Payne, A. 2008. Handbook Of CRM: Achieving Excellence in Customer Management. Great Britain: Elsevier Ltd. h. 4-6. 
memberikan manfaat apa-apa, jika proses tersebut tidak menghasilkan perilaku pelanggan yang diharapkan perusahaan ${ }^{6}$. CRM yang sukses harus memiliki sinergi people (sumber daya manusia), process (teknologi), quality (barang dan jasa) dan fokus pelanggan?. Pilihan akhir pada konstruk penelitian pada perilaku pelanggan berdasarkan kinerja CRM sebagai salah satu sinergi terwujudnya manajemen hubungan pelanggan adalah pilihan yang strategis.

Merujuk pada beberapa fenomena yang berkembang dalam industri ini yaitu, pertama melihat adanya perubahan cara pandang dalam industri ini dari Business to Business dan atau Business to Customer. Kerangka piker Business to Business dan atau Business to Customer adalah aktivitas bisnis perusahaan ditujuan untuk keuntungan perusahaan, dan atau kepuasan pelanggan. Sementara pada industri keuangan saat ini, telah terjadi pergeseran dan atau perubahan dalam cara pandang dan berpikir pada Customer to Business dan atau Customer to Customer, yaitu keuntungan atau kinerja perusahaan dapat terwujud sesuai dengan harapan melalui aktivitas yang dilakukan pelanggan secara sadar untuk kepentingan perusahaan, Pemilihan Perum pegadaian syariah di Jambi merujuk pada beberapa data penunjang lain seperti adanya data Laporan Keuangan Pegadaian.

Melalui riset, pihak pegadaian dapat mengetahui pengaruh kompetensi sumber daya manusia, mutu pelayanan pegadaian syariah dan teknologi yang berorientasi pada nasabah berdasarkan kinerja CRM yang menjadikan pilihan nasabah bertransaksi dipegadaian syariah. Dari hasil tersebut, pihak pegadaian dapat setiap saat menyesuaikan diri dengan perubahan keinginan dan kebutuhan masyarakat. Bertitik tolak dari latar belakang masalah di atas, maka

${ }^{6}$ Wang, Yonggui., Hing Po lo, Renyong Chi., and Yongheng Yang (2004), “ An Integrated Frame Work For Customer Value And Customer-Relationship-Management Performance: a customer-based perspective from China “Managing Service Quality, Vol. 14, p. 169-182.

${ }^{7}$ Silva, Rui Vinhas Da., and, Iian Rahimi (2007), " A critical success factor model for CRM implementation ", International Journal Electronic Customer Relationship Management, Vol. 1 No.1. p. 3-15. 
penulis tertarik untuk mengadakan pengkajian lebih mendalam mengenai strategi Customer Relationship Management (CRM) pada perum pegadaian syariah.

\section{Identifikasi Masalah}

a. Terjadinya persaingan pasar yang semakin kompleks dan munculnya lembaga keuangan baru dimana mereka berlombalomba memberikan layanan yang kian beragam dan menarik untuk mempengaruhi kepuasan dan loyalitas nasabah

b. Adanya faktor yang mempengaruhi tingkat kepuasan dan loyalitas nasabah pada pegadaian syariah di Provinsi Jambi

c. Pegadaian syariah membutuhkan strategi Customer Relationship Management (CRM) yang lebih optimal untuk meningkatkan kepuasan dan loyalitas nasabah.

d. Pentingnya Mengukur kinerja strategi Customer Relationship Management (CRM) melalui kompetensi sumber daya manusia, Kualitas pelayanan, dan Teknologi serta upaya yang dilakukan agar mampu bersaing dan bertahan ditengah banyak nya persaingan lembaga keuangan lainya, dengan menggunakan strategi manajemen hubungan pelanggan pada perum pegadaian syariah di Provinsi Jambi.

\section{Teori/Kajian}

\section{a. Customer Relationship Management (CRM)}

Dalam kondisi pasar yang kompetitif, perusahaan harus berjuang bertahan hidup, membuktikan bahwa membangun dan mengelola hubungan dengan pelanggan adalah sangat penting. Dasar dari setiap hubungan jangka panjang, terletak kepuasan pelanggan. Kepuasan terkait pada interaksi dengan penyedia layanan, sehingga penting dan harus selalu dievaluasi. ${ }^{8}$

Manajemen hubungan pelanggan atau yang biasa dikenal Customer Relationship Management (CRM) adalah suatu proses dalam

${ }^{8}$ Bena, I. 2010. "Evaluating Customer Satisfaction In Banking Services”, Management \& Marketing. Vol. 5, Edisi 2; pg. 143, 8 pgs. 
mendapatkan, mempertahankan dan meningkatkan hubungan pelanggan yang menguntungkan dengan tujuan untuk menciptakan nilai pelanggan, sehingga pelanggan puas dan memaksimalkan keuntungan bagi perusahaan memperoleh dalam rangka memperoleh keunggulan bersaing (comparative advantage), memperhatikan mutu produk agar dapat memberikan kepuasan yang prima bagi pelanggan. ${ }^{9}$ Kotler \& Amstrong menyatakan manajemen hubungan pelanggan adalah proses keseluruhan untuk membangun dan menjaga hubungan dengan pelanggan melalui pemberian nilai pelanggan superior dan kepuasan pelanggan. ${ }^{10}$

Arti kontemporer CRM (Customer Relationship Management) dianggap sebagai strategi bisnis dari tahun 1990an, dan kemudian dikembangkan untuk memilih dan mengelola hubungan pelanggan yang paling berharga. Secara umum, Gartner Group pertama kali berteori konsep manajemen hubungan pelanggan pada tahun 1999. Ini mendefinisikan CRM (Customer Relationship Management) sebagai strategi bisnis yang bertujuan untuk mengsegmentasikan pasar pelanggan, loyalitas pelanggan dan menggabungkan keuntungan dan pendapatan yang maksimal Dan Kepuasan pelanggan. ${ }^{11}$

Payne dan frow menyebutkan bahwa CRM merupakan pendekatan strategis yang berkaitan dengan menciptakan nilai pemegang saham yang ditingkatkan melalui pengembangan yang tepat hubungan dengan pelanggan utama dan segmen pelanggan. CRM menyatukan potensi strategi pemasaran hubungan dan Teknologi informasi untuk menciptakan hubungan jangka panjang yang menguntungkan dengan pelanggan dan pemangku kepentingan utama lainnya. CRM memberikan peningkatan peluang untuk digunakan data dan informasi untuk memahami pelanggan dan menciptakan nilai bersama mereka. Pada konsep CRM membutuhkan

\footnotetext{
${ }^{9}$ Buchari Alma, Pengantar Bisnis (Bandung: Alfabeta, 2010), h. 296.

${ }^{10}$ Kotler, Phillip \& Garry Armstrong, Principles of Marketing. 11 th Edition, (Prentice Hall International Inc. New Jersey. 2006), h.16.

${ }^{11}$ Tavana, et. al., "Theoretical Models of Customer Relationship Management in Organizations”. International Journal of Business and Behavioral Sciences (E-journal). 20133 (11), h. 63.
} 
integrasi lintas fungsi dari proses, orang, operasi, dan kemampuan pemasaran yang diaktifkan melalui informasi, teknologi, dan aplikasi. $^{12}$

Menurut Chen dan Popovich terdapat tiga elemen utama yang menjadi kunci keberhasilan penerapan CRM yaitu people, process, dan technology. Ketiga hal tersebut tidak dapat dilakukan secara sendirisendiri. Di mana ketiga hal ini akan bergantung satu sama lain sehingga tercipta suatu strategi bisnis yang baik ${ }^{13}$. Sin et,al., juga menjelaskankan bahwa sukses dan tidaknya manajemen hubungan pelanggan setidaknya dipengaruhi adanya sinergi antara people (sumber daya manusia), quality (mutu barang dan jasa), process (teknologi) dan fokus pelanggan. ${ }^{14}$

CRM, juga baru-baru ini disebut 'manajemen pelanggan', adalah sebuah bisnis pendekatan yang berupaya menciptakan, mengembangkan, dan meningkatkan hubungan dengan pelanggan yang ditargetkan dengan hati-hati untuk meningkatkan nilai pelanggan dan profitabilitas perusahaan dan karenanya memaksimalkan nilai pemegang saham. CRM sering dikaitkan dengan pemanfaatan informasi teknologi untuk menerapkan strategi pemasaran hubungan pelanggan. CRM dapat menyatukan potensi teknologi baru dan pemasaran untuk menghasilkan hubungan jangka panjang yang menguntungkan. ${ }^{15}$

Costumer Relationship Management (CRM) atau manajemen hubungan nasabah merupakan kombinasi dari orang-orang (people), proses dan teknologi yang berusaha untuk memahami pelanggan

${ }^{12}$ Jacob Z. Haislip, Vernon J. Richardson. "The effect of Customer Relationship Management Systems on Firm Performance" International Journal of Accounting Information Systems 27 (2017) h. 16-29.

${ }^{13}$ Chen, I.J. \& Popovich, K.. “Understanding Customer Relationship Management (Crm) - People, Process And Technology”. Business Process Management .Vol. 9 No. 5, 2003, h. 672 - 688.

${ }^{14}$ Sin, “CRM: Conceptualization And Scale Development", European Journal of Marketing, vol. 39, No. 12, 2005, h. 1264-1290.

${ }^{15}$ Adrian Payne, HANDBOOK OF CRM: Achieving Excellence in Customer Management, (Butterworth-Heinemann is an imprint of Elsevier Linacre House, Jordan Hill, Oxford, 2005), h.17. 
perusahaan. Abdul Manap mendefinisikan Costumer Relationship Management (CRM) sebagai suatu strategi bisnis yang bertujuan untuk menciptakan teknologi informasi dalam perusahaan yang akan membantu sistem manajemen mendengaran pelanggan. Menurut Clay dan Maite yang dikutip oleh Abdul Manap juga menyebutkan hal yang sama bahwa CRM merupakan suatu konsep yang bertujuan untuk membuat hubungan jangka panjang yang menguntungkan dengan pelanggan, dan konsep ini menjembatani antara strategi pemasaran dan teknologi informasi. ${ }^{16}$

\section{Tujuan Penulisan}

Tujuan utama dari penelitian ini adalah untuk menguji pentingnya CRM pada sektor pegadaian syariah. Tujuan khusus lain dari penelitian adalah:

a. Untuk meninjau konsep dan literatur tentang strategi dan mekanisme penggunaan (Customer Relationship Management) CRM pada pegadaian syariah.

b. Untuk menganalisis dampak dan efesiensi pengaruh kompetensi sumber daya manusia, mutu pelayanan dan teknologi terhadap kepuasan nasabah berdasarkan kinerja (Customer Relationship Management) CRM pada nasabah pegadaian syariah.

c. Untuk menganalisis Seberapa besar pengaruh kepuasan nasabah terhadap loyalitas nasabah berdasarkan kinerja (Customer Relationship Management) CRM pada nasabah pegadaian syariah.

\section{B. Metodologi}

\section{Metodologi Penelitian}

Metode yang digunakan dalam penelitian ini adalah deskriptif analisis dan metode kuantitatif. Untuk jenis penelitian deskriptif yang digunakan adalah penelitian studi kasus. Lokasi Penelitian ini dilaksanakan di Perum Pegadaian Syariah di Provinsi Jambi yang

${ }^{16}$ Muhammaad Adam, Manajemen Pemasaran Jasa, (Bandung: Alfabeta, 2015), h. 70 . 
terdiri dari 5 kantor Unit pembantu di wilayah Kabupaten/Kota, Populasi dalam penelitian ini adalah seluruh nasabah yang memakai produk gadai pada Pegadaian Syariah di provinsi Jambi. Untuk menentukan sampel dari Perum Pegadaian Syariah di Provinsi Jambi dapat digunakan perhitungan Hair yaitu pada jumlah indikator penelitian dikalikan 5 sampai 10. Dengan demikian sampel untuk penelitian ini adalah:

Jumlah Sampel $=$ Jumlah Indikator X 5

22 X 5 = 110 sampel

Hal ini merujuk pada Hair bahwa jumlah sampel (responden) yang dipakai dalam penelitian yang menggunakan SEM minimum 100 sampel. Merujuk pada persyaratan dan rumus sampel yang dianjurkan oleh Hair maka 110 sampel telah cukup memenuhi syarat. ${ }^{17}$ Sumber data yang diperlukan dalam penelitian ini adalah

a. data primer data yang diperoleh peneliti langsung dari informasi melalui sumber pertama melalui wawancara dan hasil-hasil yang diperoleh dari observasi di lapangan yang direkam melalui catatan tertulis peneliti ${ }^{18}$. Didalam penelitian ini data primer didapat dari pengisian kuesioner oleh nasabah dan data yang diambil dari Pegadaian Syariah untuk mengetahui tanggapan responden mengenai

1) Kompetensi sumber daya manusia

2) Mutu pelayanan

3) Teknologi

b. Data sekunder yaitu data yang diperoleh secara tidak langsung, melalui dokumentasi dan buku-buku yang berhubungan dengan masalah yang dihadapi.dan tidak langsung berhubugan dengan responden yang akan diteliti dan merupakan pendukung bagi peneliti yang akan dilakukan.

${ }^{17}$ Hair, Joseph F.JR., Rolph E. Anderson, Ronald L. Tatham, and William C. Black,(1995)," Multivariate Data Analysis With Readings," Fourth Edition, New Jersey: Prentice Hall, h. 10

18 Muhamad, Metodologi Penelitian Ekonomi Islam, (Jakarta: Raja Grafindo Persada, 2008.), h. 103. 
Untuk mengolah data penelitian ini menggunakan bantuan aplikasi Software statistik. Metode analisis yang dipilih untuk menganalisis data menggunakan SEM (Structural Equation Model) dari paket statistik AMOS. Penelitian ini akan menggunakan dua macam teknik analisis yaitu :

a. Confirmatory Factor Analysis pada SEM yang digunakan untuk mengkonfirmasikan faktor-faktor yang paling dominan dalam satu kelompok variabel.

b. Regression Weight pada SEM yang digunakan untuk meneliti seberapa besar hubungan antar variabel.

\section{Hipotesis Penelitian}

Berdasarkan permasalahan yang ada, maka penulis membuat hipotesis sebagai berikut.

Tabel 3

\begin{tabular}{|c|l|}
\hline \multicolumn{3}{|c|}{ HIPOTESIS } \\
\hline Hipotesis 1 & $\begin{array}{l}\text { Kompetensi sumber daya manusia berpengaruh } \\
\text { terhadap kepuasan nasabah }\end{array}$ \\
\hline Hipotesis 2 & $\begin{array}{l}\text { Mutu pelayanan pegadaian syariah berpengaruh } \\
\text { terhadap kepuasan nasabah }\end{array}$ \\
\hline Hipotesis 3 & $\begin{array}{l}\text { Teknologi pegadaian syariah berpengaruh terhadap } \\
\text { kepuasan nasabah }\end{array}$ \\
\hline Hipotesis 4 & $\begin{array}{l}\text { Kepuasan nasabah berpengaruh terhadap loyalitas } \\
\text { nasabah berdasarkan kinerja CRM }\end{array}$ \\
\hline
\end{tabular}

\section{Pembahasan}

\section{Temuan Penelitian}

Estimasi measurement model dengan teknik confirmatory factor analysis yang digunakan untuk menguji unidimensionalitas dari konstruk-konstruk eksogen dan endogen. Model pengukuran untuk analisis faktor konfirmatori yaitu pengukuran terhadap dimensidimensi yang membentuk variabel laten/konstruk laten dalam model penelitian, yaitu: kompetensi sumber daya manusia, mutu pelayanan, dan teknologi sebagai konstruk eksogen. Sedangkan kepuasan nasabah, dan loyalitas nasabah berdasarkan kinerja CRM sebagai 
konstruk endogen. Unidimensionalitas dari dimensi-dimensi ini diuji melalui analisis faktor konfirmatori.

\section{a. Analisis Faktor Konfirmatori Eksogen}

Model pengukuran untuk analisis faktor konfirmatori eksogen yaitu pengukuran terhadap dimensi-dimensi yang membentuk variabel laten/konstruk laten dalam model penelitian, yaitu kompetensi sumber daya manusia, mutu pelayanan dan teknologi. Unidimensionalitas dari dimensi-dimensi ini diuji melalui analisis faktor konfirmatori eksogen seperti dalam Gambar berikut ini.

\section{Gambar 1}

\section{Analisis Faktor Konfirmatori Eksogen}

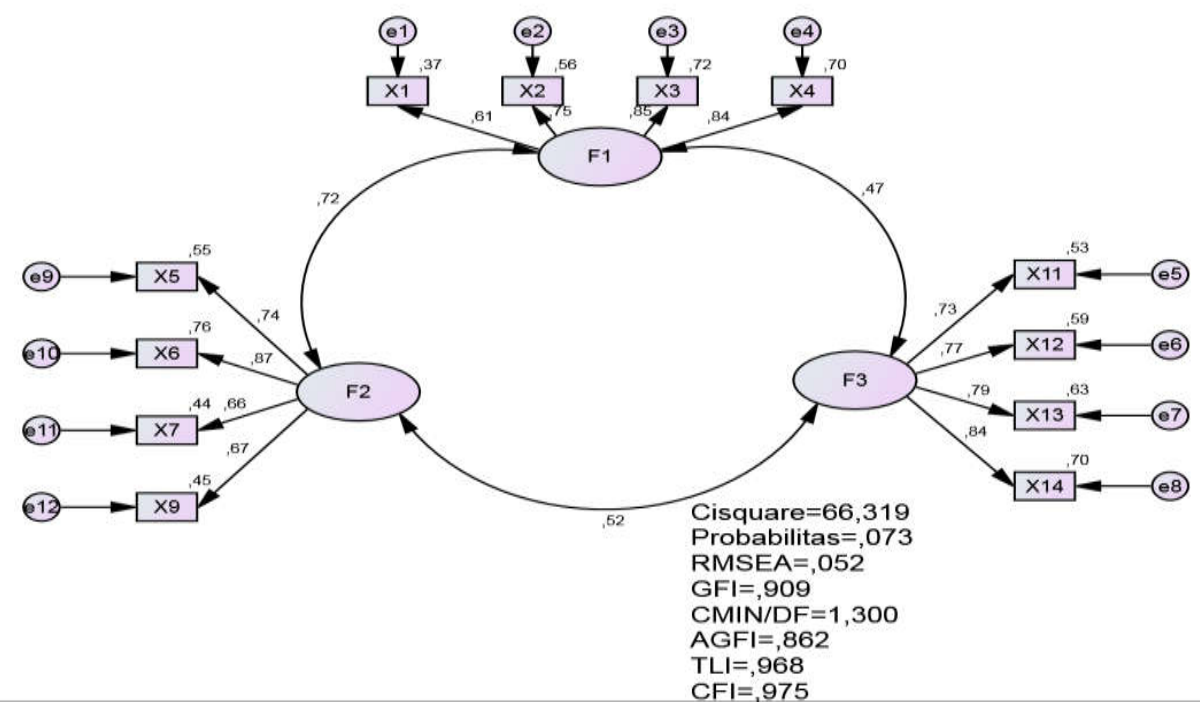


Tabel 4

Hasil Uji Model Faktor Konfirmatori Konstruk eksogen

\begin{tabular}{|l|l|l|l|}
\hline $\begin{array}{l}\text { Goodness of fit } \\
\text { index Cut-of Value }\end{array}$ & Cut-of Value & Hasil & Evaluasi \\
\hline $\begin{array}{l}\chi^{2}-\text { Chi-square } \\
\text { Significancy }\end{array}$ & $\begin{array}{l}\text { p dengan }: 51 ; \\
68,66929\end{array} \%$ & 66,319 & baik \\
\hline Probability & $\geqslant 0.05$ & 0,73 & baik \\
\hline RMSEA & $\leqslant 0,08$ & 0,52 & baik \\
\hline GFI & $\geqslant 0.90$ & 0,909 & baik \\
\hline AGFI & $\geqslant 0.90$ & 0,862 & marginal \\
\hline CMIN/DF & $\leqslant 2,00$ & 1,300 & baik \\
\hline TLI & $\geqslant 0.95$ & 0,968 & baik \\
\hline$C F I$ & $\geqslant 0.95$ & 0,975 & baik \\
\hline
\end{tabular}

Berdasarkan hasil pengamatan pada gambar pada grafik analisis faktor konfirmatori pada konstruk eksogen dapat ditunjukkan bahwa model layak diuji pada tahap full model. Hasil perhitungan chi-square pada konstruk eksogen memperoleh nilai sebesar 66,319 masih dibawah chi-square tabel untuk derajat kebebasan 74 pada tingkat signifikan 5 \% sebesar 95,081. Nilai probabilitas sebesar 0,073 yang mana nilai tersebut diatas 0,05. Nilai CMIN/DF sebesar 1,300 sehingga masih dibawah 2,00. Nilai GFI sebesar 0,909 di atas 0,90 dan AGFI sebesar 0,862 yaitu lebih kecil dari 0,90 (marginal). Nilai TLI sebesar 0,968 yang mana masih diatas 0,95 . Nilai CFI sebesar 0,975 yang mana nilainya masih diatas 0,95 , dan nilai RMSEA sebesar 0,052 yang mana nilai tersebut masih dibawah 0,08. Hasil tersebut menunjukkan bahwa konstruk memenuhi kriteria model fit (Goodness of-Fit Indices). Disamping kriteria diatas observed (indikator) dari kompetensi sumber daya manusia, mutu pelayanan, dan teknologi adalah valid, karena mempunyai nilai louding diatas 0,5 sehingga tidak satupun observed 
(indikator) yang didrop (dibuang). Hasil tersebut menunjukkan konstruk dapat diolah dengan full model. Kuat lemahnya dimensidimensi untuk membentuk faktor latennya dapat dianalisis dengan menggunakan uji t terhadap Regression Weights sebagaimana tersaji dalam Tabel 5 dan dengan melihat faktor loading masing-masing dimensi tersebut.

Tabel 5

Regression Weights: (Group number 1 - Default model)

\begin{tabular}{|c|c|c|c|c|c|c|c|}
\hline \multicolumn{3}{|c|}{} & Estimate & S.E. & C.R. & P & Label \\
\hline X1 & $<---$ & F1 & 1,000 & & & & \\
\hline X2 & $<---$ & F1 & 1,361 &, 221 & 6,145 & $* * *$ & \\
\hline X3 & $<---$ & F1 & 1,336 &, 201 & 6,651 & $* * *$ & \\
\hline X4 & $<---$ & F1 & 1,544 &, 234 & 6,595 & $* * *$ & \\
\hline X11 & $<---$ & F3 & 1,000 & & & & \\
\hline X12 & $<---$ & F3 & 1,036 &, 139 & 7,448 & $* * *$ & \\
\hline X13 & $<---$ & F3 & 1,007 &, 131 & 7,681 & $* * *$ & \\
\hline X14 & $<---$ & F3 & 1,021 &, 127 & 8,016 & $* * *$ & \\
\hline X5 & $<---$ & F2 & 1,000 & & & & \\
\hline X6 & $<---$ & F2 & 1,159 &, 137 & 8,458 & $* * *$ & \\
\hline X7 & $<---$ & F2 &, 819 &, 124 & 6,614 & $* * *$ & \\
\hline X9 & $<---$ & F2 &, 940 &, 140 & 6,714 & $* * *$ & \\
\hline
\end{tabular}

Berdasarkan hasil pada Tabel 5 di atas terlihat bahwa setiap indikator atau dimensi pembentuk masing-masing variabel laten menunjukkan hasil yang memenuhi kriteria yaitu nilai Critical Ratio (CR) $>1.96$ dengan Probability (P) lebih kecil dari pada 0,05.

\section{b. Analisis Faktor Konfirmatori Endogen}

Estimasi structural equation model melalui analisis Full Model untuk melihat kesesuaian model dan hubungan kausalitas yang dibangun dalam model. Model pengukuran untuk analisis faktor konfirmatori endogen yaitu pengukuran terhadap dimensi-dimensi yang membentuk variabel laten/konstruk laten dalam model penelitian, yaitu kepuasan nasabah dan loyalitas nasabah berdasarkan 
kinerja CRM. Unidimensionalitas dari dimensi-dimensi ini diuji melalui analisis faktor konfirmatori endogen seperti dalam Gambar 2 berikut ini.

\section{Gambar 2}

Faktor Konfirmatori Endogen

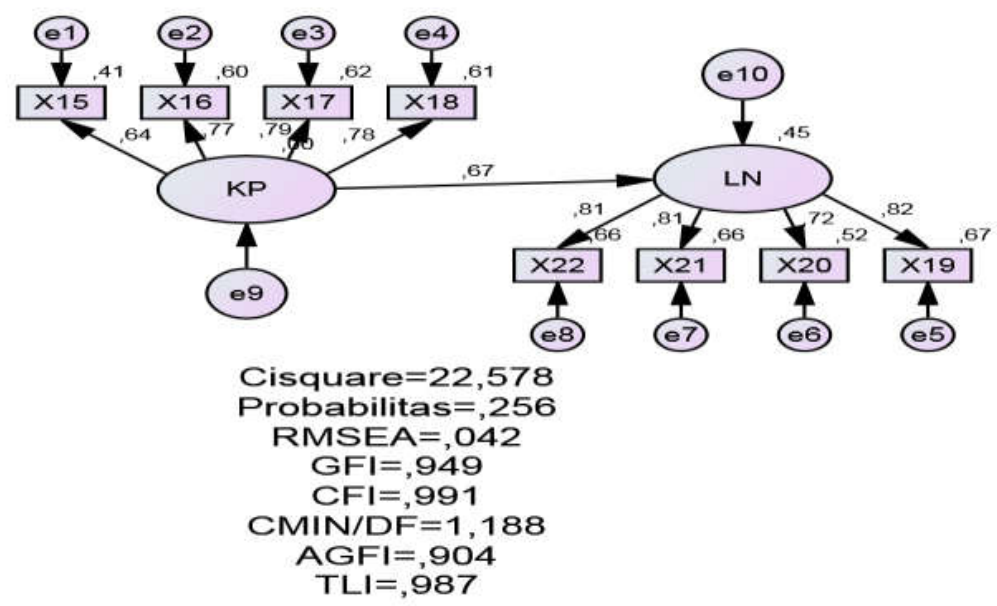

Tabel 6

Hasil Uji Model Faktor Konfirmatori Konstruk Endogen

\begin{tabular}{|l|l|c|c|}
\hline $\begin{array}{l}\text { Goodness of fit } \\
\text { index Cut-of Value }\end{array}$ & Cut-of Value & Hasil & Evaluasi \\
\hline $\begin{array}{l}\chi^{2}-\text { Chi-square } \\
\text { Significancy }\end{array}$ & $\begin{array}{l}\chi 2 \text { dengan } \mathrm{df}: \\
30,14353\end{array}$ & baik \\
\hline Probability & $\geqslant 0.05$ & 0,256 & baik \\
\hline RMSEA & $\leqslant 0,08$ & 0,42 & baik \\
\hline GFI & $\geqslant 0.90$ & 0,949 & baik \\
\hline AGFI & $\geqslant 0.90$ & 0,904 & baik \\
\hline
\end{tabular}


Analisis Strategi Customer ...

\begin{tabular}{|l|c|c|c|}
\hline$C M I N / D F$ & $\leqslant 2,00$ & 1,118 & baik \\
\hline$T L I$ & $\geqslant 0.95$ & 0,986 & baik \\
\hline$C F I$ & $\geqslant 0.95$ & 0,991 & baik \\
\hline
\end{tabular}

Berdasarkan hasil pengamatan pada gambar pada grafik analisis faktor konfirmatori pada konstruk endogen dapat ditunjukkan bahwa model layak diuji pada tahap full model. Hasil perhitungan chi-square pada konstruk endogen memperoleh nilai sebesar 22, 578 masih dibawah chi-square tabel untuk derajat kebebasan 19 pada tingkat signifikan $5 \%$ sebesar 30,14353. Nilai probabilitas sebesar 0,256 yang mana nilai tersebut diatas 0,05. Nilai CMIN/DF sebesar 1,118sehingga masih dibawah 2,00. Nilai GFI sebesar 0,949 yaitu lebih besar dari 0,90 dan AGFI sebesar 0,904 yaitu lebih besar dari 0,90. Nilai TLI sebesar 0,986 yang mana masih diatas 0,95 . Nilai CFI sebesar 0,991 yang mana nilainya masih diatas 0,95 , dan nilai RMSEA sebesar 0,042 yang mana nilai tersebut masih dibawah 0,08. Hasil tersebut bahwa konstruk memenuhi kriteria model fit (Goodness of-Fit Indices). Disamping kriteria diatas observed (indikator) dari kepuasan nasabah dan loyalitas nasabah berdasarkan kinerja CRM adalah valid, karena mempunyai nilai louding diatas 0,5 sehingga tidak satupun observed (indikator) yang didrop (dibuang). Hasil tersebut menunjukkan konstruk dapat diolah dengan full model. Kuat lemahnya dimensi-dimensi untuk membentuk faktor latennya dapat dianalisis dengan menggunakan uji t terhadap Regression Weights sebagaimana tersaji dalam Tabel 7 dan dengan melihat faktor loading masing-masing dimensi tersebut.

Tabel 7

Regression Weights: (Group number 1 - Default model)

\begin{tabular}{|l|l|r|r|r|r|r|r|}
\hline & & & Estimate & S.E. & C.R. & P & Label \\
\hline LN & $<---$ & KN &, 852 &, 164 & 5,209 & $* * *$ & \\
\hline X15 & $<---$ & KN & 1,000 & & & & \\
\hline X16 & $<---$ & KN & 1,142 &, 177 & 6,449 & $* * *$ & \\
\hline X17 & $<---$ & KN & 1,352 &, 207 & 6,526 & $* * *$ & \\
\hline
\end{tabular}


Busriadi, Muhammad Yasir Nasution, Saparuddin Siregar

\begin{tabular}{|l|l|l|r|r|r|r|r|}
\hline & & & Estimate & S.E. & C.R. & P & Label \\
\hline X18 & $<---$ & KN & 1,279 &, 197 & 6,494 & $* * *$ & \\
\hline X19 & $<---$ & LN & 1,000 & & & & \\
\hline X20 & $<---$ & LN &, 889 &, 111 & 7,979 & $* * *$ & \\
\hline X21 & $<---$ & LN & 1,046 &, 114 & 9,185 & $* * *$ & \\
\hline X22 & $<---$ & LN &, 969 &, 105 & 9,197 & $* * *$ & \\
\hline \hline
\end{tabular}

Berdasarkan hasil pada Tabel 7 di atas terlihat bahwa setiap indikator atau dimensi pembentuk masing-masing variabel laten menunjukkan hasil yang memenuhi kriteria yaitu nilai Critical Ratio (CR) >1.96 dengan Probability (P) lebih kecil dari pada 0,05. Analisis selanjutnya adalah analisis Structural Equation Model (SEM) secara Full Model yang dimaksudkan untuk menguji model dan hipotesis yang dikembangkan dalam penelitian ini. Pengujian model dalam Structural Equation Model dilakukan dengan dua pengujian, yaitu uji kesesuaian model dan uji signifikansi kausalitas melalui uji koefisien regresi. Hasil pengolahan data untuk analisis SEM terlihat pada Gambar 3.

Gambar 3

\section{Full Model}

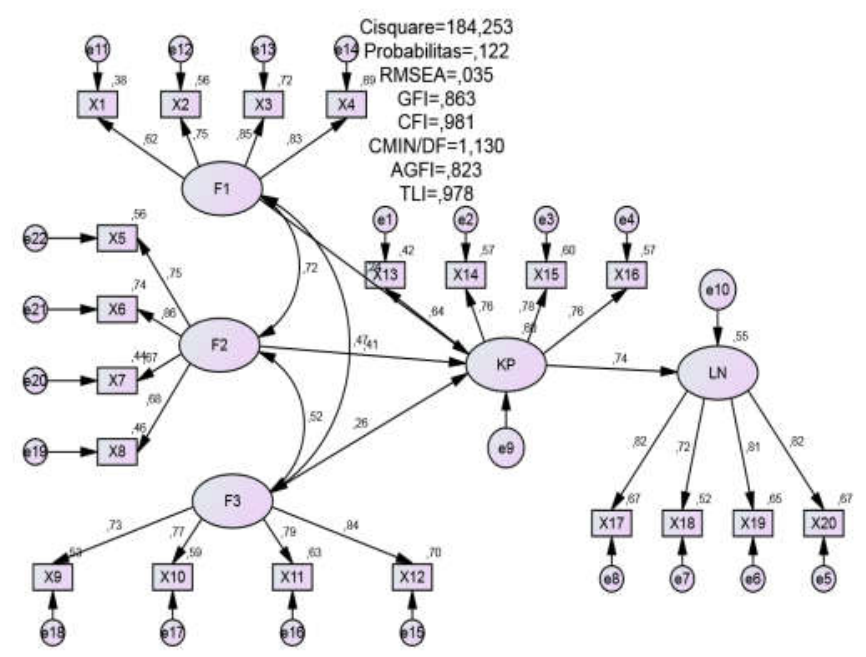


Tabel 8

Hasil Uji Full Model

\begin{tabular}{|c|c|c|c|}
\hline $\begin{array}{c}\text { Goodness of fit } \\
\text { index Cut-of } \\
\text { Value }\end{array}$ & Cut-of Value & Hasil & Evaluasi \\
\hline $\begin{array}{c}\chi^{2}-\text { Chi-square } \\
\text { Significancy }\end{array}$ & $\begin{array}{c}\chi 2 \text { dengan } \mathrm{df}: 163 ; \mathrm{p} \\
: 5 \% 193,7914\end{array}$ & 184,253 & baik \\
\hline Probability & $\geqslant 0.05$ & 0,122 & baik \\
\hline RMSEA & $\leqslant 0,08$ & 0,035 & baik \\
\hline GFI & $\geqslant 0.90$ & 0,863 & marginal \\
\hline AGFI & $\geqslant 0.90$ & 0,823 & marginal \\
\hline CMIN/DF & $\leqslant 2,00$ & 1,130 & baik \\
\hline TLI & $\geqslant 0.95$ & 0,978 & baik \\
\hline CFI & $\geqslant 0.95$ & 0,981 & baik \\
\hline
\end{tabular}

Berdasarkan hasil pengamatan pada gambar pada grafik analisis full model dapat ditunjukkan bahwa model memenuhi kriteria fit, hal ini ditandai dengan nilai dari hasil perhitungan memenuhi kriteria layak full model. Hasil perhitungan uji chi-square pada full model memperoleh nilai chi-square sebesar 184,253 masih dibawah chisquare tabel untuk derajat kebebasan 163 pada tingkat signifikan $5 \%$ sebesar 193,7914. Nilai probabilitas sebesar 0,122 yang mana nilai tersebut diatas 0,05. Nilai CMIN/DF sebesar 1,130 sehingga masih dibawah 2,00. Nilai GFI sebesar 0,863 yaitu lebih kecil dari 0,90 (marginal). Nilai AGFI sebesar 0,823 yaitu lebih kecil dari 0,90 (marginal). Nilai TLI sebesar 0,978 yang mana masih diatas 0,95 . Nilai CFI sebesar 0,981 yang mana nilainya masih diatas 0,95 dan nilai RMSEA sebesar 0,035 yang mana nilai tersebut masih dibawah 0,08. 
Hasil tersebut menunjukkan bahwa model keseluruhan memenuhi kriteria model fit.

Tabel 9

Hasil Regression Weights Analisis Struktural Equation Modeling Regression Weights: (Group number 1 - Default model)

\begin{tabular}{|l|l|l|r|r|r|r|l|}
\hline & & & Estimate & S.E. & C.R. & P & Label \\
\hline KN4 & $<---$ & ksdm1 &, 263 &, 155 & 1,695 &, 090 & par_17 \\
\hline KN4 & $<---$ & t3 &, 227 &, 094 & 2,420 &, 016 & par_18 \\
\hline KN4 & $<---$ & MP2 &, 360 &, 139 & 2,595 &, 009 & par_19 \\
\hline LN4 & $<---$ & KN4 &, 906 &, 166 & 5,465 & $* * *$ & par_1 \\
\hline X13 & $<---$ & KN4 & 1,000 & & & & \\
\hline X14 & $<---$ & KN4 & 1,114 &, 170 & 6,571 & $* * *$ & par_2 \\
\hline X15 & $<---$ & KN4 & 1,330 &, 200 & 6,661 & $* * *$ & par_3 \\
\hline X16 & $<---$ & KN4 & 1,238 &, 192 & 6,435 & $* * *$ & par_4 \\
\hline X20 & $<---$ & LN4 & 1,000 & & & & \\
\hline X19 & $<---$ & LN4 & 1,067 &, 119 & 8,991 & $* * *$ & par_5 \\
\hline X18 & $<---$ & LN4 &, 911 &, 115 & 7,939 & $* * *$ & par_6 \\
\hline X17 & $<---$ & LN4 & 1,033 &, 111 & 9,327 & $* * *$ & par_7 \\
\hline X1 & $<---$ & ksdm1 & 1,000 & & & & \\
\hline X2 & $<---$ & ksdm1 & 1,339 &, 211 & 6,355 & $* * *$ & par_8 \\
\hline X3 & $<---$ & ksdm1 & 1,319 &, 195 & 6,759 & $* * *$ & par_9 \\
\hline X4 & $<---$ & ksdm1 & 1,514 &, 234 & 6,473 & $* * *$ & par_10 \\
\hline X12 & $<---$ & t3 & 1,000 & & & & \\
\hline X11 & $<---$ & t3 &, 986 &, 106 & 9,279 & $* * *$ & par_11 \\
\hline X10 & $<---$ & t3 & 1,014 &, 121 & 8,375 & $* * *$ & par_12 \\
\hline X9 & $<---$ & t3 &, 986 &, 127 & 7,755 & $* * *$ & par_13 \\
\hline X8 & $<---$ & MP2 & 1,000 & & & & \\
\hline X7 & $<---$ & MP2 &, 871 &, 140 & 6,225 & $* * *$ & par_14 \\
\hline X6 & $<---$ & MP2 & 1,216 &, 165 & 7,351 & $* * *$ & par_15 \\
\hline X5 & $<---$ & MP2 & 1,067 &, 162 & 6,572 & $* * *$ & par_16 \\
\hline
\end{tabular}


Berdasarkan pada Gambar 3 dan Tabel 9 bahwa setiap indikator pembentuk variabel laten menunjukkan hasil yang memenuhi kriteria yaitu nilai CR di atas 1,96 dengan $P$ lebih kecil dari pada 0,05 dan nilai lambda atau factor loading yang lebih besar dari 0,5. Hasil tersebut dapat dikatakan bahwa indikator-indikator pembentuk variabel laten tersebut secara signifikan merupakan indikator dari faktor-faktor laten yang dibentuk.

\section{Pembahasan}

Pengujian hipotesis dididasarkan atas pengolahan data penelitian dengan menggunakan analisis SEM, dengan cara menganalisis nilai regresi. Pengujian hipotesis ini dilakukan dengan menganalisis nilai C.R (Critical Ratio) dan nilai P (Probability) pada hasil olah data Regression Weights, dibandingkan dengan batasan statistik yang disyaratkan, yaitu nilai CR (Critical Ratio) di atas 1,96 dan nilai P (Probability) di bawah 0.05. Apabila hasilnya menunjukkan nilai yang memenuhi syarat tersebut, maka hipotesis penelitian yang diajukan dapat diterima.

Secara rinci pengujian hipotesis penelitian akan dibahas secara bertahap sesuai dengan hipotesis yang telah diajukan. Pada penelitian ini diajukan empat hipotesis yang selanjutnya pembahasannya dilakukan dibagian berikut ini.

\section{a. Uji Hipotesis I}

Hipotesis I pada penelitian ini adalah kompetensi sumber daya manusia tidak berpengaruh signifikan terhadap kepuasan nasabah, apabila kompetensi sumber daya manusia rendah, maka semakin rendah tingkat kepuasan nasabah. Berdasarkan data dari hasil pengolahan data diketahui bahwa nilai CR (Critical Ratio) untuk hubungan antara variabel kompetensi sumber daya manusia seperti terlihat pada Tabel 4.18 adalah sebesar 1,695 dengan nilai $P$ (Probability) sebesar 0,090. Kedua nilai ini menunjukkan hasil yang tidak memenuhi syarat, yaitu diatas 1,96 untuk CR (Critical Ratio) dan di bawah 0.05 untuk nilai $\mathrm{P}$ (Probability). Sehingga dapat dapat disimpulkan bahwa hipotesis 1 pada penelitian ini di tolak. 


\section{b. Uji Hipotesis II}

Hipotesis II pada penelitian ini adalah Mutu pelayan berpengaruh signifikan terhadap kepuasan nasabah, sehingga semakin tinggi mutu pelayanan maka semakin tinggi kepuasan nasabah. Berdasarkan data dari hasil pengolahan data diketahui bahwa nilai CR (Critical Ratio) untuk hubungan antara variabel kompetensi sumber daya manusia seperti terlihat pada Tabel 4.18 adalah sebesar 2,595 dengan nilai P (Probability) sebesar 0,09. Kedua nilai ini menunjukkan hasil yang memenuhi syarat, yaitu di atas 1,96 untuk CR (Critical Ratio) dan dibawah 0.05 untuk nilai P (Probability). Sehingga dapat dapat disimpulkan bahwa hipotesis II pada penelitian ini di terima.

\section{c. Uji Hipotesis III}

Hipotesis III pada penelitian ini adalah teknologi berpengaruh signifikan terhadap kepuasan nasabah, sehingga semakin tinggi teknologi maka semakin tinggi kepuasan nasabah. Berdasarkan data dari hasil pengolahan data diketahui bahwa nilai CR (Critical Ratio) untuk hubungan antara variabel kompetensi sumber daya manusia seperti terlihat pada Tabel 4.18 adalah sebesar 2,420 dengan nilai $\mathrm{P}$ (Probability) sebesar 0,016. Kedua nilai ini menunjukkan hasil yang memenuhi syarat, yaitu di atas 1,96 untuk CR (Critical Ratio) dan di bawah 0.05 untuk nilai $\mathrm{P}$ (Probability). Sehingga dapat dapat disimpulkan bahwa hipotesis III pada penelitian ini di terima.

\section{d. Uji Hipotesis IV}

Hipotesis IV pada penelitian ini adalah kepuasan nasabah berpengaruh signifikan terhadap loyalitas nasabah, sehingga semakin tinggi kepuasan nasabah maka semakin tinggi loyalitas nasabah. Berdasarkan data dari hasil pengolahan data diketahui bahwa nilai CR (Critical Ratio) untuk hubungan antara variabel kompetensi sumber daya manusia seperti terlihat pada Tabel 4.18 adalah sebesar 5,465 dengan nilai $\mathrm{P}$ (Probability) sebesar 0,000. Kedua nilai ini menunjukkan hasil yang memenuhi syarat, yaitu di atas 1,96 untuk CR (Critical Ratio) dan di bawah 0.05 untuk nilai P (Probability). Sehingga 
dapat dapat disimpulkan bahwa hipotesis IV pada penelitian ini di terima.

\section{Penutup}

Mengenai kesimpulan atas hasil analisis data dan diterimanya hipotesis-hipotesis, kesimpulan hipotesis yang didasarkan atas analisis data yang telah dilakukan pada pembahasan sebelumnya. Selanjutnya dirumuskan kesimpulan penelitian terhadap empat hipotesis ini diuraikan sebagai berikut ;

1. Hipotesis 1 yang diajukan pada penelitian ini adalah kompetensi sumber daya manusia berpengaruh positip dan signifikan terhadap kepuasan nasabah. Berdasarkan hasil analisis data maka penelitian ini berhasil membuktikan dan selanjutnya menyimpulkan bahwa pada variabel kompetensi sumber daya manusia belum berpengaruh positip dan signifikan terhadap kepuasan nasabah. Berdasarkan kesimpulan tersebut maka hipotesi 1 di tolak.

2. Hipotesis 2 yang diajukan pada penelitian ini adalah mutu pelayanan berpengaruh positif dan signifikan terhadap kepuasan nasabah. Berdasarkan hasil analisis data maka penelitian ini berhasil membuktikan dan selanjutnya menyimpulkan bahwa mutu pelayanan bank berpengaruh positif terhadap kepuasan nasabah, sehingga semakin tinggi mutu pelayanan maka semakin tinggi kepuasan nasabah. Selanjutnya dari peryataan hipotesis tersebut penelitian ini dapat menyimpulkan bahwa; Hipotesis yang dibangun dalam penelitian ini memperkuat justifikasi hipotesis penelitian terdahulu, di mana mutu pelayanan berpengaruh terhadap kepuasan pelanggan.

3. Hipotesis 3 yang diajukan pada penelitian ini adalah teknologi berpengaruh positif terhadap kepuasan nasabah. Berdasarkan hasil analisis data maka penelitian ini berhasil membuktikan dan selanjutnya menyimpulkan bahwa teknologi berpengaruh positif dan signifikan terhadap kepuasan nasabah, sehingga semakin tinggi teknologi maka semakin tinggi kepuasan nasabah. Selanjutnya dari peryataan hipotesis tersebut penelitian ini dapat menyimpulkan bahwa Hipotesis yang dibangun dalam penelitian ini memperkuat 
justifikasi hipotesis penelitian terdahulu, Penelitian ini berhasil menyimpulkan bahwa teknologi berpengaruh positif dan signifikan terhadap kepuasan nasabah adalah benar atau valid berdasarkan uji analisis data yang telah dilakukan.

4. Hipotesis 4 yang diajukan pada penelitian ini adalah kepuasan nasabah berpengaruh positif dan signifikan terhadap loyalitas nasabah. Berdasarkan hasil analisis data maka penelitian ini berhasil membuktikan dan selanjutnya menyimpulkan bahwa kepuasan nasabah berpengaruh positif dan signifikan terhadap loyalitas nasabah, sehingga semakin tinggi kepuasan nasabah maka semakin tinggi loyalitas nasabah. Selanjutnya dari peryataan hipotesis tersebut penelitian ini dapat menyimpulkan bahwa Hipotesis yang dibangun dalam penelitian ini memperkuat justifikasi hipotesis penelitian terdahulu dan Penelitian ini berhasil menyimpulkan bahwa kepuasan nasabah berpengaruh positif dan signifikan terhadap loyalitas nasabah adalah benar atau valid berdasarkan uji analisis data yang telah dilakukan.

\section{Daftar Pustaka}

Adam , Muhammaad, Manajemen Pemasaran Jasa, Bandung: Alfabeta, 2015.

Adrian Payne, HANDBOOK OF CRM: Achieving Excellence in Customer Management, (Butterworth-Heinemann is an imprint of Elsevier Linacre House, Jordan Hill, Oxford, 2005.

Bena, I. "Evaluating Customer Satisfaction In Banking Services”, Management \& Marketing. Vol. 5, Edisi 2; pg. 143, 2010.

Buchari Alma, Pengantar Bisnis Bandung: Alfabeta, 2010.

Chen, I.J. \& Popovich, K.. “Understanding Customer Relationship Management (Crm) - People, Process And Technology”. Business Process Management .Vol. 9 No. 5, 2003. 
Hair, Joseph F.JR., Rolph E. Anderson, Ronald L. Tatham, and William C. Black," Multivariate Data Analysis With Readings," Fourth Edition, New Jersey: Prentice Hall, 1995.

http://www.ojk.go.id

Jacob Z. Haislip, Vernon J. Richardson. "The effect of Customer Relationship Management Systems on Firm Performance" International Journal of Accounting Information Systems 27, 2017

Kotler, Phillip \& Garry Armstrong, Principles of Marketing. 11 th Edition, (Prentice Hall International Inc. New Jersey. 2006.

Muhamad, Metodologi Penelitian Ekonomi Islam. Jakarta: Raja Grafindo Persada, 2008.

Payne, A. Handbook of CRM: Achieving Excellence in Customer Management. Great Britain: Elsevier Ltd. 2008.

Silva, Rui Vinhas Da., and, Iian Rahimi, " A critical success factor model for CRM implementation ", International Journal Electronic Customer Relationship Management, Vol. 1 No.1, 2007.

Sin, “CRM: Conceptualization And Scale Development“, European Journal of Marketing, vol. 39, No. 12, 2005.

Tavana, et. al., “Theoretical Models of Customer Relationship Management in Organizations”. International Journal of Business and Behavioral Sciences (E-journal). 2013.

Wang, Yonggui., Hing Po lo, Renyong Chi., and Yongheng Yang “ $A n$ Integrated Frame Work For Customer Value And CustomerRelationship-Management Performance: a customer-based perspective from China “,Managing Service Quality, Vol.14, 2004.

www.pegadaian.co.id 